\title{
LEADERSHIP IN THE VALUE CHAIN
}

\author{
AD Berndt (RAU)
}

The value chain is a term that is widely used to describe the activities of the organisation. The question that can be posed refers to the effect that the knowledge of the value chain has on the organisation. It is of little benefit if the knowledge of the value chain does not translate into a tangible benefit for the organisation. The contribution of the value chain refers to the leadership and management effects within the organisation through the developm ent of a value proposition and the commitment thereto for all the activities of the organisation. The article examines the value chain concept and the effect that it can have on the development of strategy and leadership styles.

Keywords: leadership, value, value added, value chain, value proposition, value system

\section{THE VALUE CHAIN CONCEPT}

The value chain is regarded as an important way of examining the activities of organisations. This concept has the possibility of revolutionising the way in which business is done as well as the internal arrangement of the organisation. The traditional approach to doing business started with the organisation examining its assets, resources and skills and determining what product can be brought into the market place and sold to generate a profit (known as the supply approach to business). As times and the environment have changed, so organisations have discovered that this approach cannot work, and they are required to ensure they are customer orientated and focused on satisfying customer needs. It is here that the value chain concept has been introduced and where its value can be identified.

\section{The Value Chain defined}

The value chain can be defined as the "tool that is used to disaggregate a business into strategically relevant activities" (Walters \& Lancaster 2000:160). The term "strategically relevant activities" refers to the functions, and the decision needs to be made as to what functions are important from a strategic perspective within the organisation. These functions need to operate effectively and add value if the organisation is to be profitable.

The value chain (see Figure 1) enables the organisation to determine their significant activities while also determining their ability to create customer value through its activities (Nieman \& Bennett 2002:14). This customer focus is supported by a further definition of the value chain, namely that it is "a business system which creates end-user satisfaction (i.e. value) and realises the objectives of other member stakeholders" (Walters \& Lancaster 2000:162).

\section{Primary and secondary activities in the value chain}

According to the value chain concept, the following primary activities can be identified: 
- Inbound logistics: this refers to getting inputs from suppliers which are used in the production process and the storage of goods until they are needed.

- Operations: the actual production process that takes place

- Outbound logistics: the activities required to get the products to the consumers (through the use of intermediaries) and includes activities such as warehousing and transportation.

- Marketing and sales: the activities to encourage the actual sales of the product among the members of the target market.

- Service: this refers to customer service offered once the product has been sold, and includes customer training and installation.

\section{Figure 1: The generic value chain}

\begin{tabular}{|c|c|c|c|c|c|c|}
\hline \multirow{5}{*}{$\begin{array}{r}\text { SUPPORT } \\
\text { ACTIVITIES }\end{array}$} & \multicolumn{5}{|c|}{ Firm infrastructure } & \multirow{5}{*}{ Margin } \\
\hline & \multicolumn{5}{|c|}{ Human Resource Management } & \\
\hline & \multicolumn{5}{|c|}{ Technology development } & \\
\hline & \multicolumn{5}{|c|}{ Procurement } & \\
\hline & $\begin{array}{l}\text { Inbound } \\
\text { logistics }\end{array}$ & Operations & $\begin{array}{l}\text { Outbound } \\
\text { logistics }\end{array}$ & $\begin{array}{l}\text { Marketing \& } \\
\text { Sales }\end{array}$ & Service & \\
\hline
\end{tabular}

Source: Kippenberger 1997:7

Further, secondary or support activities can be identified by the value chain:

- Infrastructure of the organisation: general management activities including financial management, corporate affairs and quality management

- Human Resource (HR) Management: all matters to do with the attraction, maintenance and training of staff throughout the organisation

- Technology development: engineering and process development

- Procurement i.e. the function of purchasing for the organisation

\section{Key terms in the value chain}

In the value chain, a number of key concepts summarise this approach:

Value (or value added): the utility combination of benefits delivered to a customer less the total costs of acquiring the benefits. This means that the selling price (or the market value) 
minus the costs required to generate the income will indicate the degree of the value added. Another way of defining value added is "the market value exceeds the costs of the inputs" (Nieman \& Bennett 2002: 11).

Value proposition: this refers to the value that is delivered to customers. The focus of the value chain is the issue of the value proposition that the organisation has. From an external perspective, it is the way in which the organisation positions itself in the mind of the target market. The value proposition has two components - the emotional benefits that it promises to the customer (feelings, atmosphere) and the functional aspects associated with the product (taste, colour, characteristics of the product). This enables the organisation to identify the value drivers that it offers the target market as well as the activities that are needed to bring this about. The value proposition also functions are the primary organising principle (Walters \& Lancaster 2000:160).

Value system: many different people use the term "value chain" when in fact they are referring to a supply chain. A supply chain refers to all activities that commence with the supplier and ends when the product reaches the consumer (Nieman \& Bennett 2000:16). For this reason, Porter uses the term "value system", which includes the buyer value chain, the supplier value chain and the channel value chain (Kippenberger 1997:8).

Figure 2: $\quad$ The value system

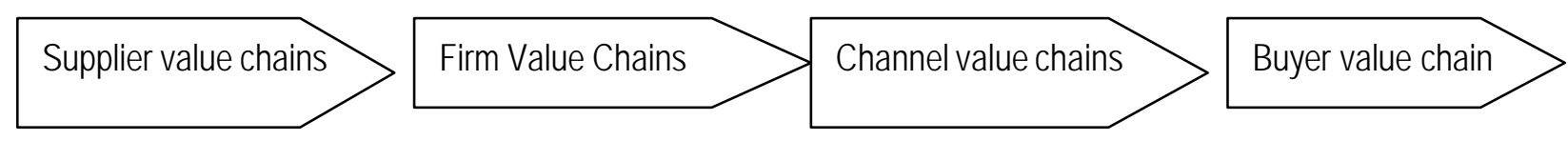

Source: Kippenberger 1997: 8

\section{The importance of the value chain approach}

There are a number of reasons why the value chain approach is important within organisations.

- The value chain enables the organisation to derive the value proposition and mission.

The value chain can hence indicate a strategic direction for the organisation. The value chain enables the organisation to identify the key components that will give a competitive edge in the market place. Organisations are continually seeking a competitive advantage, and the keys to the competitive advantage can be found within the value system of the organisation.

- It causes the organisation to focus on those activities that add value. Organisations have a tendency to become involved in many different activities. A way of deciding whether the activity should continue is to determine the extent to which it adds value for the organisation. Once the core activities have been identified, the balanced of the activities can be outsourced to other parties to focus on. 
Links in the chain (the relationships formed)

There are linkages within the value chain where there are relationships between the activities. All functions will affect the way in which another function operates, or affects the costs in those functions. In order to facilitate interaction between the linkages, the organisation has to develop an organisational structure that encourages interaction as well as examining the nature of communication and co-operation.

Getting the functions to work together can take place through vertical coordination and through the development of a co-destiny (or shared purpose) (Walters \& Lancaster 2000:164).

It is important to remember that the parts of the organisation do not function individually rather they are required to interact if the organisation is to be successful as a unit. Through creating a common purpose, integration of functions is necessary.

\section{EFFECT OF THE VALUE CHAIN ON MANAGEMENT}

Knowledge of the value chain must be applied within the organisation if we are to derive benefit from it (as a concept). The effect of the value chain is seen in the strategy that is developed to exploit the competitive advantage that has been identified. It is not only on the strategy that the value chain has an effect, but it also requires a mindset shift on the part of the employees of the organisation - who are now required to become customer and value proposition orientated.

\section{The effect on strategy}

Strategy can be seen as the process of "creating value"(Walters \& Lancaster 2000:161). It can also be seen as the way in which the organisation reaches its goals (Thompson \& Strickland 2003:48).

The effect that the value chain concept has on the organisation is the guidance that it provides in the generation of strategy. All strategy is thus developed in the light of the value proposition. Six principles of strategy development can be developed in the light of the value chain (Porter 2001: 66).

- The right goal: Superior long term ROI is usually the long term goal for the organisation. This then serves as the basis for all the strategy development.

- The strategy must enable the organisation to deliver on the value proposition. The strategy (action plan) needs to indicate what has to be done to make the value proposition a reality and so bring it about.

- Strategy needs to be reflected in a distinctive value chain. The value chain forms the basis of competition between various organisations. The value chain needs to be different (more competitive) than that offered by others in the market place. It has to be adapted to 
the organisation's unique value proposition. Very often adopting best practices makes the organisation just like all its competitors as all organisations implement best practices! It is a case of being better than the rest and doing things better than your competitors. Part of this process can involve a benchmarking exercise to ensure that the value chain is distinctive.

- Robust strategies involve trade-offs - where sacrifices are made in order to be unique. This may mean that the organisation has to sacrifice some characteristics to be good at others. It is not possible to be all things to all people - this will result in no competitive advantage.

- Strategy defines how all the elements of what a company does, fit together. All the activities in the organisation should reinforce the way in which business is done. The organisation as a whole competes, and what is required is an interdependent unit that will be successful in the market place. The strength and competitiveness of the organisation comes from the team concept - where the team at its broadest comprises the functions and at its smallest, work groups within the organisation.

- Strategy involves continuity of direction - what the organisation will stand for over time. When organisations are continually "re-organising" or "re-engineering", it could be interpreted as a lack of strategic direction. A long term strategic direction is the continuity in the face of changing times, and is derived from the value chain.

\section{Benchmarking}

Competitiveness raises the question of benchmarking within the context of the value chain. Benchmarking comes about when the organisation compares its costs of an activity with the costs of the competitor (Thompson \& Strickland 2003:134). In this activity, the organisation will compare the way they perform their activities with the way in which the competitors carry out the same activity. This will indicate the best practices for a specific industry. The purpose of benchmarking is to compare the costs of activities as well as identify the best practices that exist. It also enables the organisation to identify their competitive position with regard to these practices. The challenge is to gain the information on the activities and practices of the competitors, which tend to be kept confidential.

\section{What specific value chain strategies can be selected?}

Porter identified a number of generic strategies that can be linked to the analysis of the value chain. These strategies are cost leadership, differentiation and a focus strategy (Walters \& Lancaster 1999b: 651).

\section{Cost leadership as a strategy}

In order to be a cost leader in an industry, there are three areas that can receive the organisation's attention (Strickland \& Thompson 2003:138).

- Suppliers as a source of costs: In order to reduce these, lower costs can be negotiated or alternative sources of supply or alternative products can be identified. Collaboration with suppliers can also be used to lower costs (such as Just-in-time) as well as backward vertical integration (getting control over the suppliers and the sources thereof). 
- Distributors and intermediaries as a source of costs: Costs can be lowered through pressure on intermediaries to lower costs, to assist the intermediary in finding ways to lower costs and identifying more economical distribution strategy options can also be considered.

- The costs associated with internal activities: these costs can be lowered through the revamping of the value chain and outsourcing hose that are not regarded as primary activities. Opportunities for cost saving need to be identified, as in the use of new technology, cost-saving best practices as well as encouraging innovation in the areas that are cost drivers. Other examples of reconfiguring the value chain include shifting to $e$ business technologies, using direct selling methods, simplifying product design and stripping away any extra aspects associated with the product.

\section{Differentiation as a strategy}

Generally the existing products of an organisation are not sufficient to provide a competitive advantage. The competitive advantage of an organisation centres on market-related competencies as well as things that please customers (that the competitors do not have or can not acquire readily). This is usually done by the organisation identifying specific aspects of the product that make the product valuable, hence different from those of the competitors. Differentiation can be based on features of the product or service. This reflects in the value chain being adapted to reflect use of internal activities to make the differentiation attributes possible.

Focus (or niche) as a strategy

Here the organisation focuses on a portion of the total market rather than the market as a whole. The target market is thus specific and linked to a specific geographical area, a product or attributes required of the product as part of their manufacturing process. The niche has to be profitable and the demand has be such that it is sustainable.

\section{The effect of the value chain on leadership}

Leadership is "accomplishing the group purpose", which requires not only effective leaders, but also innovators, entrepreneurs and thinkers who require "resources, questions of value and social cohesion" (Horner 1997: 274).

Leadership theories have focused on different things over time. Trait theory focused on the personality characteristics of the leader to attempt to determine one personality trait that makes a person a good leader. Behavioural theory (Herzberg, Maslow, Blake \& Mouton) determined that successful leadership is in the behaviour exhibited by the leader (task and people-orientated leaders). Situational leadership examined the success of a leader in a specific situation - and that some leaders were more successful than others (Winston Churchill and Britain at war). Leadership theories have changed to reflect the changing views of what makes a leader.

The most recent development of leadership has identified the development of SuperLeadership. In the case of the value chain, SuperLeadership can be regarded as the most appropriate for the challenges that organisations will face in the future. Business is 
different today - information is at the core and there is a need for speed and efficiency. This affects the expectations of team members as well as affecting the work environment.

SuperLeadership is a set of strategies that to enable a person to develop a higher work performance and effectiveness, taking on increasing amounts of responsibility internally (Horner 1997: 279). It is a strategy that is based on the following:

- There is a group goal to which the team is striving. (Without this common goal, there is nothing to bind the team together)

- The leader is not the only skilled person in the group. In fact, while the organisation may view the person as the leader, anyone in the team can be the leader at any time. In the group, social and group dynamics will determine the effectiveness of the group. The resources available to the team also determine team effectiveness.

- Anyone can be a team leader, though they currently are not recognised as such by the organisation. There are no specific characteristics that will make this person a leader.

- The focus moves from being able to manage others, to being able to manage self. Selfleadership within the individual receives more attention than the actions of a few select people. Self-management refers to the discipline that a person has over their tasks and the way in which the tasks are carried out. The effect of this change is that the need for traditional supervisors is decreasing.

This means the role of the traditional leader will change from a traditional perspective (setting assignments, evaluating performance) to a new nature of activities (facilitation, coaching, mentoring and the management of relationships outside of the team). Leaders are thus providing the support, coaching and facilitation to enable the team members to work efficiently and effectively.

\section{The effect of the value chain on team members}

The importance of self-management is identified with SuperLeadership. To be an effective member of a team means that you have to exhibit self-management as well as being willing and able to participate within a team, and sometime to act as the leader, at appropriate times.

Other actions required of team leaders are the evaluation of personal actions, performance management and personal accountability. This means that all are required to show leadership characteristics.

This self-leadership is placed within an organisational context - in respect of the mission, goals and common purpose of the organisation.

\section{CONCLUSION}

The value chain serves to indicate key activities in the organisation that affect the strategic direction taken. The value chain also contributes to the identification of key activities that are incorporated in the selection of strategy. In implementing the value chain concept, other aspects such as corporate culture and knowledge management also require attention. 


\section{BIBLIOGRAPHY}

BACKHOUSE CJ \& BURNS ND. 1999. Agile value chains for manufacturing - implications for performance measures. International Journal of Agile Management Systems, 1(2): 76 - 82.

HORNER M. 1997. Leadership Theory: past, present and future. Team Performance Management, 3(4): 270287.

KIPPENBERGER T. 1997. The Value chain - the original breakthrough. The Antidote, 8:7-9.

LEE CC \& YANG J. 2000. Knowledge Value Chain. Journal of Management Development, 19(9):783-794.

MAGRETTA J. 1998. Fast, Global and Entrepreneurial: Supply chain management, Hong Kong style. Harvard Business Review, 75 (5):102-115.

NIEMAN G \& BENNETT A eds. 2002. Business Management: A Value Chain Approach. Pretoria: Van Schaik.

PORTER M. 2001. Strategy and the Internet. Harvard Business Review, 79(3):62-79.

THOMPSON AA \& STRICKLAND AJ. 2003. Strategic management: concepts and cases. $13^{\text {th }}$ ed. Boston: McGraw-Hill Irwin.

WALTERS D \& LANCASTER G. 1999a. Value-based marketing and its usefulness to customers. Management Decision, 37(9): 697-708.

WALTERS D \& LANCASTER G. 1999b. Value and information. Management Decision, 37(8):643-656.

WALTERS D \& LANCASTER G. 2000. Implementing value strategy through the value chain. Management Decision, 38(3):160-178. 